\title{
Incidence of Sports-Related Traumatic Brain Injury of All Severities: A Systematic Review
}

\author{
Alice Theadom ${ }^{a}$ Susan Mahon ${ }^{a}$ Patria Hume ${ }^{a, b} \quad$ Nicola Starkey ${ }^{c}$ \\ Suzanne Barker-Collo ${ }^{d}$ Kelly Jones $^{a}$ Marek Majdan $^{\mathrm{e}}$ Valery L. Feigin ${ }^{a}$ \\ aNational Institute for Stroke and Applied Neuroscience, School of Public Health and Psychosocial Studies, \\ Auckland University of Technology, Auckland, New Zealand; 'b Sports Performance Research Institute New Zealand, \\ School of Sport and Recreation, Auckland University of Technology, Auckland, New Zealand; ' Division of Arts, Law, \\ Psychology and Social Sciences, School of Psychology, University of Waikato, Hamilton, New Zealand; ${ }^{\mathrm{d} S c h o o l ~ o f ~}$ \\ Psychology, Faculty of Science, University of Auckland, Auckland, New Zealand; ${ }^{\text {Department }}$ of Public Health, \\ Faculty of Health Sciences and Social Work, Trnava University, Trnava, Slovakia
}

\section{Keywords}

Incidence · Sport · Brain injury · Concussion · Epidemiology

\begin{abstract}
Introduction: Whilst there are many benefits to participating in sports and recreational activities, there is also a risk of injury including sports-related traumatic brain injury (SR-TBI). To inform injury prevention initiatives, it is important to explore the burden of SR-TBI at the population level. This review aimed to estimate the incidence of SR-TBI in the general population across injury severities. Methods: Systematic search of electronic databases using keywords from 1965 until June 2019 facilitated by hand searches of reference lists. Original research reporting on the incidence of SR-TBI, capturing people of all ages in a well-defined population area was included. Studies were excluded if they focused on a specific sport(s) or population group. All studies were required to be published in the English language. Quality of studies was determined as poor, moderate or good based on the standards of reporting of neurological disorders criteria. Data on year(s) of data collection, diagnostic criterion, case ascertainment sources, population denominator and inci-
\end{abstract}

dence per 100,000 and by age, sex, injury severity and sport were extracted by 2 authors independently using a standard data extraction form. Results: Following review of 11 studies meeting the inclusion criteria, the incidence of SR-TBI within hospital-based studies ranged between 3.5 and 31.5 per 100,000 . One community-based study using multiple case ascertainment sources identified a higher incidence of 170 per 100,000 . SR-TBI accounted for $1.2-30.3 \%$ of all TBIs. One study provided incidence data across a 5-year period suggesting an increasing trend in incidence over time. Males were more at risk than females (66.1-75.6\%), and adolescents and young adults had the highest incidence of SR-TBI. Conclusion: The primary objective of this review was to provide a summary of descriptive data on SR-TBI epidemiology at the population level. SR-TBI represented up to one-third of all causes of TBI. Trends in incidence by age and sport were challenging to determine due to lack of consistency in reporting as well as the small number of studies overall. Undertaking injury surveillance at all levels of TBI will assist with understanding the nature, mechanism of and surrounding events where injuries occur in sport.

(c) 2020 S. Karger AG, Basel

\section{KARGER}

(c) 2020 S. Karger AG, Basel

karger@karger.com

www.karger.com/ned
Alice Theadom

National Institute for Stroke and Applied Neuroscience

Auckland University of Technology

Auckland 1142 (New Zealand)

E-Mail alice.theadom@aut.ac.nz 


\section{Introduction}

In the US alone, it is estimated that 214 million children and adults participate in some form of sports-related activity [1]. Sports-related activities are broadly defined as "participation in a specified activity for the purpose of competition or pleasure involving physical exertion and skill that may follow rules or require the use of specific equipment (such as a ball) to complete" [2]. Whilst there are considerable physical, social and mental health benefits of participating in sport [3], there is also a risk of sustaining injury, including sports-related traumatic brain injury (SR-TBI).

SR-TBI are believed to account for up to $20 \%$ of all TBIs (including concussion) [2], with half of these occurring in children and adolescents [4]. Concussion has been described as being a subset of $\mathrm{mTBI}[5,6]$. This is due to the classification of the acute injury characteristics being at the less severe end of the brain injury spectrum reflecting no neurosurgical significance of a pathological injury [5-7].

Overall, the incidence of TBI is increasing globally [8] with this increase also being observed within the sports context [1]. Reasons for increasing incidence may include improved medical coding of TBI, awareness of concussion and the need to seek medical treatment following injury as well as an actual increase in the number of injuries sustained as more people are engaging in sport. Whilst most TBI symptoms recover spontaneously in the initial days and weeks following injury, there is evidence that up to $20 \%$ of people experiencing SR-TBI can experience chronic symptoms. Both acute and chronic symptoms can include cognitive and balance difficulties, headaches, fatigue and dizziness as well as emotional disturbance (such as increased irritability or low mood) and sleep difficulties [9]. In some cases, there may also be a risk of longer-term health and cognitive problems, particularly following multiple TBIs $[10,11]$. Severity of acute symptoms, a positive history of prior TBIs and psychological factors have been found to be the most consistent predictors of delayed recovery [1215].

Many studies have been conducted exploring the incidence of TBI in particular sports, especially in contact sports such as rugby and football [16-18]. Sport-specific studies have revealed that incidence of TBI is higher in match play than in training, with increased risk in females [18]. Incidence and severity of injury have been found to vary by position played [19] and also increase with age/ duration of involvement in the sport [20].

Incidence of Sports-Related TBI
Whilst it is important to look at concussion within specific sports to identify unique aspects of that sport which impact on TBI risk to inform injury prevention initiatives, one of the challenges of exploring TBI within specific sports is that often the full spectrum of TBI severity is overlooked (e.g., many studies only include concussions or mild TBIs). Additionally, it is difficult to make comparisons between and across sports to inform population-level injury prevention strategies and to ensure messaging to the general public is relevant. Finally, studies tend to focus on particular age groups (e.g., high school or college athletes), the most popular sports (thereby overlooking the impact of less popular sports on total TBI burden) or those participating at the elite level, restricting generalisability of results to the general population (e.g., including those participating in that sport within the community). It is also important to place SR-TBI within the wider context of TBI to determine its relative contribution to overall TBI burden and whether it should be a priority in TBI prevention compared to other causes. Hospital-based studies can significantly underestimate incidence as many people do not go to hospital following mild injuries [21]. Consequently, it is important to explore SR-TBI at the population level.

The aim of this review was to determine the state of the current evidence on the incidence of SR-TBI of all severities within a general population context.

\section{Methods}

A TBI was defined as an alteration in brain function, or other evidence of brain pathology, caused by an external force [22]. A population-based study was defined as research that includes all cases of a disease (in this case TBI) occurring in an entire region [23].

\section{Search Strategy for Identification of Publications}

Records published up to 18-19 June 2019 were identified through a search of PubMed, SPORTDiscus (EBSCO), Web of Science Core Collection, Scopus, MEDLINE (EBSCO), CINAHL (EBSCO), and ScienceDirect databases (Fig. 1). The search of relevant research studies included combinations of brain injury keywords ("concuss*” OR "brain inj*” OR "head inj*” OR "tbi” OR "skull fracture" OR "head trauma"), sport-related keywords ("athlet*” OR "sport*” OR "play*”) and methodological keywords ("Inciden*” OR "epidemiol*” OR "frequenc*” OR "prevalence"). A second search was run with the additional keywords "craniocerebral trauma" and "head impact," but these additional search terms did not yield any additional articles that met the inclusion criteria and so the data are not reported.

\section{Study Selection}

The results from the search strategy yielded a total of 457 citations, with 15 citations identified from a hand search of studies of reference lists including 2 published TBI incidence reviews as 


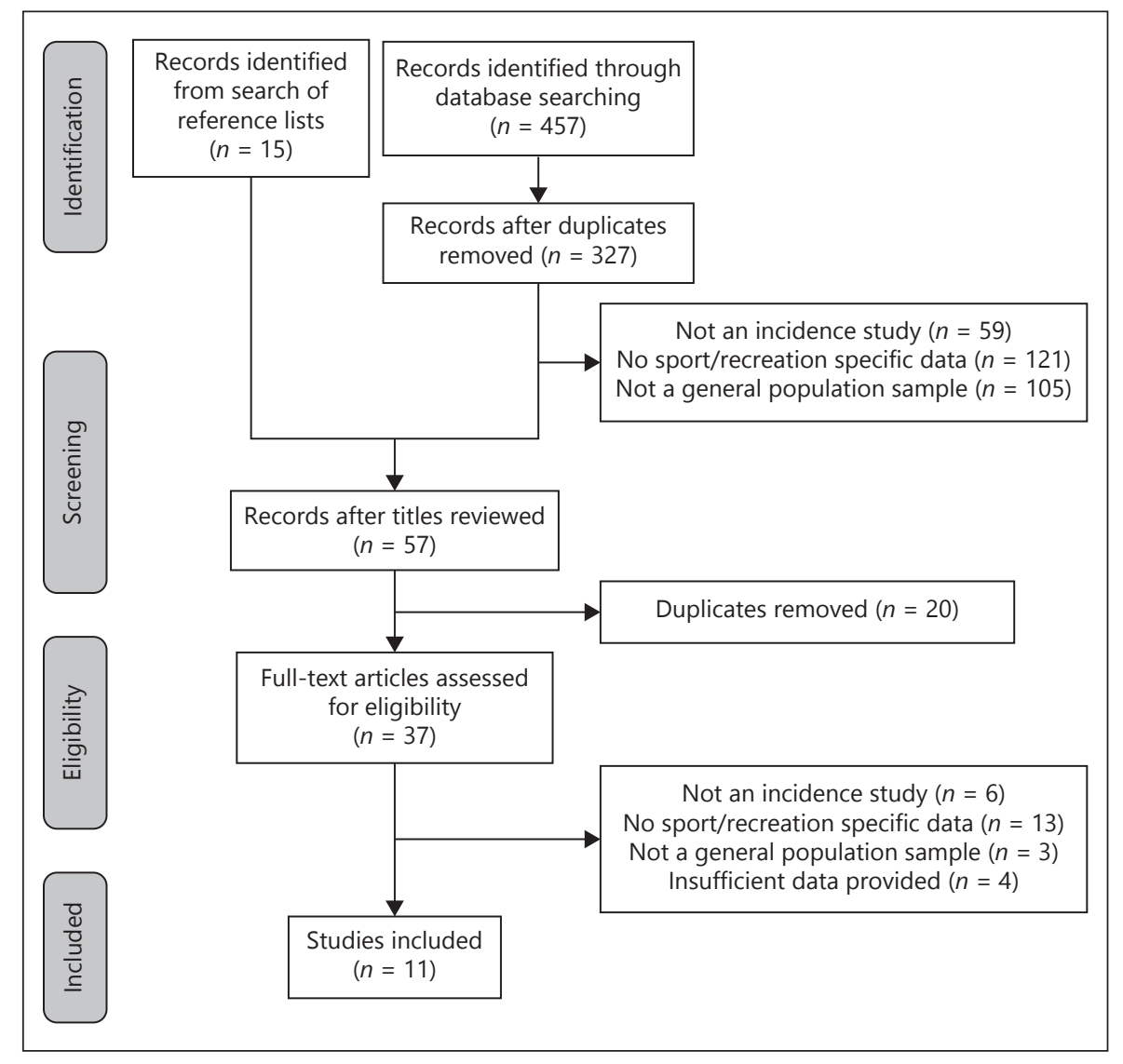

Fig. 1. Selection of studies.

shown in Figure $1[24,25]$. All references were downloaded into an excel database, and duplicate records were identified and removed. Where there was uncertainty of eligibility, the record was retained to enable further details to be ascertained to inform the final decision. Full-text articles were obtained for all potentially eligible studies and evaluated against the inclusion criteria. Papers were included if they met the following criteria: available in English; studies of human participants; published in a peer-reviewed journal; original epidemiological research; reported the incidence of SR-TBI/concussion within a general population sample (including people of all ages and all TBI severities). To capture studies reporting on SR-TBI as part of all-cause TBI, a search of studies from 2 existing TBI incidence study reviews was also completed in addition to searches of reference lists of included articles [24, 25].

Randomised controlled trials, case-control studies, qualitative, cross-sectional designs, case series, and case studies were excluded. Given the focus on population-level incidence, studies were excluded if they only looked at a subpopulation (e.g., <18 years of age or males), focused on a particular severity of injury (e.g., moderate and severe) or only reported data for a specific sport (e.g., football) or collection of sports (e.g., contact sports). Studies were also excluded if an incidence rate was not reported, and raw data were inadequate to confidently calculate incidence per 100,000 people.

Data Extraction

Two reviewers (A.T. and S.M.) extracted data from the included articles using a standard data extraction form that included first author, year, country, case definition, case ascertainment sources, number of TBI cases and population denominator. Incidence estimates were extracted along with any SR-TBI data by age, gender, TBI severity and sport type. Age and severity data were reported based on definitions used by the authors. In cases where there were multiple years of data, all data were extracted.

\section{Methodological Quality and Risk of Bias Assessment}

The quality of reporting of the included studies was independently assessed by 2 reviewers (A.T. and S.M.) using the standards of reporting of neurological disorders checklist [26]. The guideline provides a 15 -item checklist to facilitate a critical appraisal of the reporting of the study and for the interpretation of the results. Two reviewers (A.T. and S.M.) determined whether each study met the 15 criteria. The included studies were categorised as either low, moderate or good based on the percentage of fulfilled items on the standards of reporting of neurological disorders checklist, with cut-off values of $<50,50-80$ and $>80 \%$, respectively [27].

\section{Results}

Characteristics of the 11 studies meeting the eligibility criteria are shown in Table 1 . There were 3 studies including data from the USA [28-30], 2 from Norway 
Table 1. Characteristics of included studies and incidence of SR-TBI

\begin{tabular}{|c|c|c|c|c|c|c|c|c|}
\hline Study & $\begin{array}{l}\text { Study } \\
\text { timeframe }\end{array}$ & $\begin{array}{l}\text { Case } \\
\text { ascertainment } \\
\text { sources }\end{array}$ & $\begin{array}{l}\text { Number of } \\
\text { SR-TBI } \\
\text { incidents }\end{array}$ & $\begin{array}{l}\text { Population } \\
\text { denominator }\end{array}$ & $\begin{array}{l}\text { Percentage } \\
\text { of total TBI }\end{array}$ & Definition of TBI & $\begin{array}{l}\text { Crude } \\
\text { incidence of } \\
\text { SR-TBI per } \\
100,000\end{array}$ & $\begin{array}{l}\text { Percentage } \\
\text { of STROND } \\
\text { criteria met }\end{array}$ \\
\hline $\begin{array}{l}\text { Austria } \\
\text { Mauritz et al. } \\
{[30], 2014}\end{array}$ & $2009-2011$ & $\begin{array}{l}\text { Hospital discharges, } \\
\text { outpatients and } \\
\text { deaths }\end{array}$ & 3,970 & $\begin{array}{l}25,061,810 \text { over } 3 \text { years } \\
\text { (data received from } \\
\text { author) }\end{array}$ & 5.4 & $\begin{array}{l}\text { ICD-10 codes; S01.0-S06.9, T01.0, } \\
\text { T02.0, T04.0, T06.0, T90.1, T90.2, } \\
\text { or T90.4-T90.9 }\end{array}$ & 15.8 & Moderate \\
\hline $\begin{array}{l}\text { The Netherlands } \\
\text { Scholten et al. } \\
{[31], 2014}\end{array}$ & $2010-2012$ & $\begin{array}{l}\text { Emergency } \\
\text { department } \\
\text { visits, hospital } \\
\text { admissions } \\
\text { and deaths }\end{array}$ & 2,824 & $16,575,000$ & 8.2 & $\begin{array}{l}\text { ICD- } 9 \text { codes; } 850,800-801,803 \text {, } \\
804,851-854,905,907,950,959 \\
\text { Concussion or other skull injury, } \\
\text { brain injury }\end{array}$ & 17.0 & Moderate \\
\hline $\begin{array}{l}\text { Germany } \\
\text { Rickels et al. } \\
{[32], 2010}\end{array}$ & $2000-2001$ & $\begin{array}{l}\text { Hospital department } \\
\text { admissions }\end{array}$ & 427 & $2,200,000$ & 6.3 & $\begin{array}{l}\text { ICD-10 codes; SO2, SO4, SO6, } \\
\text { SO7, S09 }\end{array}$ & 19.4 & Moderate \\
\hline $\begin{array}{l}\text { Norway } \\
\text { Ingebrigtsen et al. } \\
{[35], 1998}\end{array}$ & 1993 & $\begin{array}{l}\text { Emergency } \\
\text { department visits } \\
\text { and hospital } \\
\text { admissions }\end{array}$ & 16 & 108,017 & 7.0 & $\begin{array}{l}\text { Physical damage to brain or skull } \\
\text { caused by an external force }\end{array}$ & 14.8 & Moderate \\
\hline $\begin{array}{l}\text { Edna et al. } \\
{[29], 1984}\end{array}$ & $1979-1980$ & $\begin{array}{l}\text { Hospital } \\
\text { admissions }\end{array}$ & 156 & 562,298 & 13.9 & $\begin{array}{l}\text { Physical damage to brain or skull } \\
\text { caused by an external force, loss } \\
\text { of consciousness or intracranial } \\
\text { hematoma }\end{array}$ & 27.7 & Low \\
\hline $\begin{array}{l}\text { Italy } \\
\text { Servadei et al. } \\
{[33], 2002}\end{array}$ & 1998 & $\begin{array}{l}\text { Hospital } \\
\text { admissions }\end{array}$ & 34 & 970,000 & 1.2 & $\begin{array}{l}\text { ICD-9 codes; } 800-800.3,801-801.3 \\
803-803.3,850,851-851.1,852-852.1 \\
853-853.1,854-854.1\end{array}$ & 3.5 & Moderate \\
\hline $\begin{array}{l}\text { Australia } \\
\text { Tate et al. } \\
{[34], 1998}\end{array}$ & 1988 & $\begin{array}{l}\text { Hospital } \\
\text { admissions }\end{array}$ & 104 & 343,140 & 30.3 & $\begin{array}{l}\text { ICD-9 codes; } 301,800,801,803 \\
804,850-854,905,907\end{array}$ & 30.3 & Moderate \\
\hline $\begin{array}{l}\text { USA } \\
\text { Leibson et al. } \\
{[26], 2011}\end{array}$ & $1987-1999$ & $\begin{array}{l}\text { Hospital } \\
\text { admissions } \\
\text { and discharges }\end{array}$ & 355 & $1,436,529$ & 26.7 & $\begin{array}{l}\text { ICD-9 codes; } 800,801,803,804 \\
850-854,951-953,959,995\end{array}$ & 28.2 & Good \\
\hline $\begin{array}{l}\text { Selassie et al. } \\
\text { [27], } 2013\end{array}$ & $1998-2011$ & $\begin{array}{l}\text { Emergency } \\
\text { department visits, } \\
\text { hospital } \\
\text { admissions }\end{array}$ & 16,642 & $\begin{array}{l}\text { Reference to national } \\
\text { center for Health } \\
\text { statistics but specific } \\
\text { data not provided }\end{array}$ & - & ICD-9 codes; $850-854,959$ & 31.5 & Good \\
\hline $\begin{array}{l}\text { Haring et al. } \\
{[25], 2015}\end{array}$ & $\begin{array}{l}2006-2011 \\
2006 \\
2007 \\
2008 \\
2009 \\
2010 \\
2011\end{array}$ & $\begin{array}{l}\text { Emergency } \\
\text { department visits }\end{array}$ & $\begin{array}{r}487,221 \\
63,516 \\
64,981 \\
70,114 \\
90,499 \\
92,727 \\
105,384\end{array}$ & $\begin{array}{l}1,831,565,188 \\
298,431,771 \\
301,393,632 \\
304,177,401 \\
306,656,290 \\
309,326,085 \\
311,580,009\end{array}$ & - & $\begin{array}{l}\text { ICD-9 codes; 800, 801, 803, } \\
804,854\end{array}$ & $\begin{array}{l}26.6 \\
21.3 \\
21.6 \\
23.0 \\
29.5 \\
30.0 \\
33.8\end{array}$ & Moderate \\
\hline $\begin{array}{l}\text { New Zealand } \\
\text { Theadom et al. } \\
{[2], 2014}\end{array}$ & $2010-2011$ & $\begin{array}{l}\text { Emergency } \\
\text { department visits, } \\
\text { hospital } \\
\text { admissions, GPs, } \\
\text { allied health } \\
\text { referrals, verified } \\
\text { self-referrals and } \\
\text { deaths }\end{array}$ & 291 & 173,214 & 21.3 & $\begin{array}{l}\text { Acute brain injury resulting from } \\
\text { mechanical energy to the head } \\
\text { from external forces. Use of } \\
\text { ICD-10 codes and keyword } \\
\text { searches }\end{array}$ & 170.0 & Good \\
\hline
\end{tabular}

SR-TBI, sports-related traumatic brain injury; STROND, standards of reporting of neurological disorders. 
Table 2. Incidence of SR-TBI by age

\begin{tabular}{|c|c|c|c|c|c|c|c|c|c|c|c|c|c|c|}
\hline $\begin{array}{c}\text { Haring et al. [25], } \\
\text { 2015, USA }\end{array}$ & & 26.8 & 164.7 & 185.7 & 30.1 & & & & & 4.2 & & & & \\
\hline $\begin{array}{l}\text { Leibson et al. [26], } \\
\text { 2011, USA }\end{array}$ & & 15. & & & & & & & 8.8 & & & & & $<1.0$ \\
\hline $\begin{array}{l}\text { Selassie et al. [27], } \\
\text { 2013, USA }\end{array}$ & 26.7 & 61.0 & 37.2 & & 39.9 & & 20.5 & & 12.8 & & & 6.7 & & 3.7 \\
\hline $\begin{array}{l}\text { Theadom et al. [2], } \\
\text { NZ }\end{array}$ & 6.4 & 9.8 & 34.6 & 43.9 & 23.1 & 10.4 & 12.1 & 4.0 & 8.1 & 2.3 & 5.8 & 3.5 & 4.0 & \\
\hline $\begin{array}{c}\text { Ingebrigtsen et al. } \\
\text { [28], Norway }\end{array}$ & 0 & 1.9 & 2.8 & 5.6 & 1.9 & 1.9 & 0 & 0.9 & & & & 0 & & \\
\hline
\end{tabular}

SR-TBI, sports-related traumatic brain injury.

[31, 32], 1 from Austria [33], 1 from the Netherlands [34], 1 from Germany [35], 1 from Italy [36], 1 from New Zealand [2] and 1 from Australia [37]. The studies included in this review utilised various case ascertainment sources and varied injury definitions for TBI (Table 1), which limited the interstudy comparison analyses.

\section{Sports-Related Brain Injury Incidence}

Excluding the study in New Zealand, which used a unique approach to case ascertainment and had an incidence of SR-TBI of 170.0 per 100,000, incidence ranged between 3.5 (Italy) and 31.5 (USA) per 100,000. Sportsrelated TBI was found to account for between $1.2 \%$ (in Italy) and 30.3\% (in Australia) of all TBIs.

Data were unable to be pooled as no study reported age-standardised sports-related incidence rates or data required to calculate $95 \% \mathrm{CI}$ for crude incidence rates.

\section{SR-TBI by Sex}

Only 3 studies reported data on sports-related brain injury by sex, with all studies showing that males were more at risk than females (70.4\% males in NZ [2], $66.1 \%$ males in Austria [33] and 75.6\% males in the USA) [28].

\section{SR-TBI by Age}

Five studies [2, 28-30,38] reported incidence per 100,000 by age. There were challenges in summarising the data of SR-TBI incidence by age due to the different age categories used between studies. Consequently, data are presented as categorised by the authors (Table 2). Highest incidence of SR-TBI was observed in adolescents and young adults.

\section{SR-TBI by Severity}

Two studies reported the proportion of SR-TBI by severity as classified by the Glasgow Coma Score. Theadom et al. [2] revealed that $97.6 \%$ of SR-TBI in NZ were classified in the mild range, whereas this was lower in the study in Australia [37] where only 67.3\% were in the mild range, $25 \%$ in the moderate range and $7.7 \%$ in the severe range. This may reflect differences in the case ascertainment sources utilised between the 2 studies. Haring et al. [25] in the USA classified injury severity by the Abbreviated Injury Scale and revealed that $10.2 \%$ were classified as minor, $86.3 \%$ as moderate, $2.8 \%$ as serious and $<1 \%$ as severe or critical.

\section{SR-TBI by Sport}

Only 2 studies reported the proportion of TBIs by sport as shown in Table 3. Data were only calculated by percentage to enable comparison between the 2 studies (as data per 100,000 were only available for 1 study). The sports leading to highest risk of injury included rugby/ football, off road vehicles (including cycling) and equestrian sports.

\section{Discussion}

To implement effective prevention and management strategies for SR-TBI, accurate information regarding the frequency and nature of sports-related injuries within the general population is needed. This review identified that the sports context accounted for up to onethird of all TBIs. The incidence of SR-TBI attending emergency departments, admitted to hospital or result- 
Table 3. Proportion of SR-TBI sustained by specific sports/recreation activity

\begin{tabular}{lcc}
\hline Sport & Theadom et al. & Selassie et al. [27], \\
& {$[2], 2014$ (NZ), \% } & 2013 (USA), \% \\
\hline Football/rugby & 28.5 & 38.1 \\
Equestrian & 8.9 & 9.2 \\
Cycling & 15.8 & - \\
Skateboarding & 5.2 & - \\
Hockey & 2.7 & - \\
Water-sports & 6.2 & 1.8 \\
Off-road vehicle & 8.6 & 16.1 \\
Skiing/snowboarding & 2.4 & - \\
Other & 12.4 & 14.5 \\
Unspecified & 9.3 & - \\
Falls in sport & - & 20.3 \\
\hline
\end{tabular}

SR-TBI, sports-related traumatic brain injury.

ing in death ranged between 3.5 and 31.5 per 100,000. One study providing data over multiple years suggested an increasing trend in TBI incidence. Whilst data on crude overall incidence of SR-TBI was available for 11 studies, there was a lack of standardisation in reporting and no studies reported CI or age-standardised incidence. There was a lack of detail of SR-TBI incidence by age, sex, severity or sport.

\section{Overall Incidence}

Incidence of SR-TBI ranged between 3.5 and 31.5 per 100,000 in studies looking at those who present to hospital following TBI. One study in NZ revealed a substantially higher incidence of 170 per 100,000, which may be explained by this study's community-focused approach to case ascertainment. This study specifically aimed to include those who did not seek medical treatment for their injury or who went to their GP or an allied health professional and included $36 \%$ of people with TBI who sought no healthcare services. Previous evidence suggests that many athletes either chose not to seek medical treatment for fear of missing training or an important game, lack of awareness of potential implications of the injury and lack of recognition they have sustained a brain injury [39]. These findings suggest that many people experiencing TBI may therefore not present at hospital and suggest that hospital-based studies may underestimate the actual burden of SR-TBI. However, there may be country specific differences in the management of TBI that need to be considered. For example, in NZ, people are advised to seek medical treatment for mild injuries from their GP, whereas in the paper from Austria, the authors stated that people are advised to go to the hospital for medical treatment after a TBI [40].

\section{Proportion of All-Cause TBI}

The findings from this review highlight that SR-TBI only represents up to one-third of all causes of TBI. There was considerable range by country with European countries having a much lower proportion of injuries sustained during sports-related causes $1.2-13.9 \%$, in comparison to the USA and Oceania where the proportion of SR-TBI was much higher (21.3-30.3\%). It was not clear if these findings reflected different population sports participation rates, differences in healthcare systems or TBI awareness. It may also be that the percentage of injuries for sports may be affected by coding accuracy. Whilst several studies collected data over multiple years, they only provided data for an average annual incidence. Only one study reported annual TBI incidence over a 5 -year period and suggested that there was an increasing trend in SR-TBI with incidence increasing from 21.3 per 100,000 in 2006 to 33.8 per 100,000 in 2011. This trend mirrored the increasing trends in allcause TBI globally [8], suggesting the need for both sportstargeted and generic TBI injury prevention initiatives.

The findings of this review contrasted with some of the findings from studies conducted specifically within sports or age groups. For example, previous studies revealed an increased risk in females, whereas this review suggested an increased incidence of SR-TBI in males. It may be that the contrasting findings reflect the inclusion of many different sports, with different training regimes and competition requirements, player hours and level of involvement. Indeed, previous sport-specific studies have revealed that the risk of mild TBIs is approximately 10-13x greater during competition than training practice $[1,41]$.

There were challenges in comparing SR-TBI incidence by age due to the highly variable age categories used. Overall, this review found that incidence was highest in adolescents and young adults. This is of concern as injuries sustained during this period could lead to a lifetime of burden and have a greater economic impact on society due to productivity losses. This finding contrasts with sport- and population-specific TBI studies in that TBI was previously found to increase with age in sports, which is likely to reflect prevalence rather than incidence of SR-TBI.

\section{Limitations}

Whilst the search strategy was designed to capture all relevant articles, not all eligible studies may have been identified in this review. A further limitation is that due 
to substantial differences in the reporting of studies such as use of different TBI severity categories, reported incidence by percentage rather than per 100,000 or risk and a lack of age-standardised incidence rates presented, data were unable to be pooled and cross-country comparisons were challenging. As people can experience chronic difficulties after SR-TBI, it was challenging to be able to accurately determine incidence from prevalence. Use of ICD-9 and ICD-10 codes do not enable determination as to whether the visit was for a new or previous event. In some studies, population denominator figures were not specified and only referenced, and it was difficult to obtain population denominator from the provided reference with confidence. Standards for neuroepidemiological studies were proposed in 2015 [42] after the publication of all the studies included in this review. The findings highlight the need for future studies to follow a more standardised approach for the reporting of epidemiological studies to enable international comparisons and maximising use of reported data. No population-based studies of SR-TBI were identified in Asia, South America or Africa.

A further challenge in determining incidence of SRTBI was how the mechanism of injuries was classified. All-cause TBI incidence studies often reported the mechanism using the ICD-10 external cause classification (falls, assault, exposure to mechanical force, vehicle accident). Some studies have sport as a separate category, but this then means that sports-related falls are no longer included in the falls category. Both mechanism and context/ activity are important for injury prevention, for example, knowing how many sports-related injuries are due to falls. A way forward may be to report the mechanism of TBI as in the ICD-10 and to report the context within which the injury was sustained (e.g., sport, work, activity of daily living, conflict situation, war or travelling). This further specification of the activity during which an injury is sustained could allow better targeting of preventive efforts. There is also a need to standardise the reporting of incidence by age and TBI severity to enable greater comparisons across studies. The review highlights the urgent need for higher quality, population-based studies exploring SR-TBI globally.

\section{Conclusions}

The primary objective of this review was to provide a summary of descriptive data on SR-TBI epidemiology at the population level. Low standardisation in the reporting of incidence studies and lack of data on CI and age-standardised incidence meant that data were unable to be pooled and comparisons between countries were difficult. The incidence of SR-TBI ranged between 3.5 and 31.5 per 100,000 in studies looking at those who present to hospital following TBI. SR-TBI represented up to onethird of all causes of TBI. Males were more at risk than females (66.1-75.6\%) and adolescents and young adults had the highest incidence of SR-TBI. Undertaking injury surveillance at all levels of TBI will assist with understanding the nature, mechanism of and surrounding events where injuries occur in sport.

\section{Acknowledgment}

The authors would like to thank Brigitte van Gils and Andrew South for their help and assistance in conducting the review.

\section{Disclosure Statement}

The authors declare that they were involved in 2 of the studies included in the review. The authors declare that they have no further potential conflicts of interest that are directly or indirectly relevant to the content of this review.

\section{Funding Sources}

No funding was provided for conducting this review. A.T. is supported by a Rutherford Discovery Fellowship from Government funding, administered by the Royal Society Te Apārangi.

\section{Author Contributions}

A.T., V.F., P.H., K.J., S.B.-C., and N.S. all contributed to the design of the study. A.T. and S.M. conducted the literature search, quality assessment and data extraction. A.T., V.F., P.H., K.J., S.B.C., N.S., and M.M. contributed to the analysis and interpretation of data of the work. All authors contributed to the drafting or revision of the manuscript for important intellectual content and gave their final approval of the version to be published.

References

1 Daneshvar DH, Nowinski CJ, McKee AC, Cantu RC. The epidemiology of sport-related concussion. Clin Sports Med. 2011 Jan;30(1): $1-17$.

2 Theadom A, Starkey NJ, Dowell T, Hume PA, Kahan M, McPherson K, et al.; BIONIC Research Group. Sports-related brain injury in the general population: an epidemiological study. J Sci Med Sport. 2014 Nov;17(6):5916.

Theadom/Mahon/Hume/Starkey/ Barker-Collo/Jones/Majdan/Feigin 
3 Eime RM, Young JA, Harvey JT, Charity MJ, Payne WR. A systematic review of the psychological and social benefits of participation in sport for children and adolescents: informing development of a conceptual model of health through sport. Int J Behav Nutr Phys Act. 2013 Aug; 10:98.

4 Gilchrist J, Thomas KE, Xu L, McGuire LC, Coronado VG. Nonfatal sports and recreation related traumatic brain injuries among children and adolescents treated in emergency departments in the United States, 2001-2009. MMWR Surveill Summ. 2011;60(39):1337-42.

5 Harmon KG, Drezner JA, Gammons M, Guskiewicz KM, Halstead M, Herring SA, et al. American Medical Society for Sports Medicine position statement: concussion in sport. Br J Sports Med. 2013 Jan;47(1):15-26.

6 Harmon KG, Clugston JR, Dec K, Hainline B, Herring S, Kane SF, et al. American Medical Society for Sports Medicine position statement on concussion in sport. Br J Sports Med. 2019 Feb;53(4):213-25.

7 McCrory P, Meeuwisse WH, Echemendia RJ, Iverson GL, Dvorák J, Kutcher JS. What is the lowest threshold to make a diagnosis of concussion? Br J Sports Med. 2013 Apr;47(5): 268-71.

8 James SL, Theadom A, Ellenbogen RG, Bannick MS, Montjoy-Venning W, Lucchesi LR, et al.; GBD 2016 Traumatic Brain Injury and Spinal Cord Injury Collaborators. Global, regional, and national burden of traumatic brain injury and spinal cord injury, 19902016: a systematic analysis for the Global Burden of Disease Study 2016. Lancet Neurol. 2019 Jan;18(1):56-87.

9 McCrory P, Meeuwisse W, Aubry M, Cantu $\mathrm{B}$, Dvořák J, Echemendia R, et al. Consensus statement on Concussion in Sport-the 4th International Conference on Concussion in Sport held in Zurich, November 2012. J Sci Med Sport. 2013 May;16(3):178-89.

10 Hume PA, Theadom A, Lewis GN, Quarrie KL, Brown SR, Hill R, et al. A Comparison of Cognitive Function in Former Rugby Union Players Compared with Former Non-ContactSport Players and the Impact of Concussion History. Sports Med. 2017 Jun;47(6):1209-20.

11 Manley G, Gardner AJ, Schneider KJ, Guskiewicz KM, Bailes J, Cantu RC, et al. A systematic review of potential long-term effects of sport-related concussion. Br J Sports Med. 2017 Jun;51(12):969-77.

12 Iverson GL, Gardner AJ, Terry DP, Ponsford JL, Sills AK, Broshek DK, et al. Predictors of clinical recovery from concussion: a systematic review. Br J Sports Med. 2017 Jun;51(12): 941-8.

13 Morgan CD, Zuckerman SL, Lee YM, King L, Beaird S, Sills AK, et al. Predictors of postconcussion syndrome after sports-related concussion in young athletes: a matched casecontrol study. J Neurosurg Pediatr. 2015 Jun; 15(6):589-98

14 Winblad B, Ankarcrona M, Johansson G, Novak $\mathrm{P}$, Peter Thelin E, Zetterberg $\mathrm{H}$, et al.
Head trauma in sports and risk for dementia. J Intern Med. 2019 Jun;285(6):591-3.

15 Zemek R, Osmond MH, Barrowman N; Pediatric Emergency Research Canada (PERC) Concussion Team. Predicting and preventing postconcussive problems in paediatrics (5P) study: protocol for a prospective multicentre clinical prediction rule derivation study in children with concussion. BMJ Open. 2013 Aug;3(8):e003550.

16 Gardner AJ, Iverson GL, Williams WH, Baker $\mathrm{S}$, Stanwell P. A systematic review and metaanalysis of concussion in rugby union. Sports Med. 2014 Dec;44(12):1717-31.

17 Gardner A, Iverson GL, Levi CR, Schofield PW, Kay-Lambkin F, Kohler RM, et al. A systematic review of concussion in rugby league. Br J Sports Med. 2015 Apr;49(8):495-8.

18 Prien A, Grafe A, Rössler R, Junge A, Verhagen E. Epidemiology of Head Injuries Focusing on Concussions in Team Contact Sports: A Systematic Review. Sports Med. 2018 Apr; 48(4):953-69.

19 Baugh CM, Kiernan PT, Kroshus E, Daneshvar $\mathrm{DH}$, Montenigro $\mathrm{PH}$, McKee $\mathrm{AC}$, et al. Frequency of head-impact-related outcomes by position in NCAA division I collegiate football players. J Neurotrauma. 2015 Mar; 32(5):314-26

20 Tsushima WT, Siu AM, Ahn HJ, Chang BL, Murata NM. Incidence and Risk of Concussions in Youth Athletes: Comparisons of Age, Sex, Concussion History, Sport, and Football Position. Arch Clin Neuropsychol. 2019 Feb; 34(1):60-9.

21 Brazinova A, Rehorcikova V, Taylor MS, Buckova V, Majdan M, Psota M, et al. Epidemiology of traumatic brain injury in Europe: a living systematic review. J Neurotrauma. 2018, DOI: 10.1089/neu.2015.4126.

22 Nguyen R, Fiest KM, McChesney J, Kwon CS, Jette N, Frolkis $A D$, et al. The International Incidence of Traumatic Brain Injury: A Systematic Review and Meta-Analysis. Can J Neurol Sci. 2016 Nov;43(6):774-85.

23 Bennett DA, Brayne C, Feigin VL, BarkerCollo S, Brainin M, Davis D, et al. Explanation and Elaboration of the Standards of Reporting of Neurological Disorders Checklist: A Guideline for the Reporting of Incidence and Prevalence Studies in Neuroepidemiology. Neuroepidemiology. 2015;45(2):113-37.

24 Olmos M, Antelo M, Vazquez H, Smecuol E, Mauriño E, Bai JC. Systematic review and meta-analysis of observational studies on the prevalence of fractures in coeliac disease. Dig Liver Dis. 2008 Jan;40(1):46-53.

25 Haring RS, Canner JK, Asemota AO, George BP, Selvarajah S, Haider AH, et al. Trends in incidence and severity of sports-related traumatic brain injury (TBI) in the emergency department, 2006-2011. Brain Inj. 2015;29(7-8): 989-92.

26 Leibson CL, Brown AW, Ransom JE, Diehl NN, Perkins PK, Mandrekar J, et al. Incidence of traumatic brain injury across the full disease spectrum: a population-based medical record review study. Epidemiology. 2011 Nov;22(6):836-44.

27 Selassie AW, Wilson DA, Pickelsimer EE, Voronca DC, Williams NR, Edwards JC. Incidence of sport-related traumatic brain injury and risk factors of severity: a populationbased epidemiologic study. Ann Epidemiol. 2013 Dec;23(12):750-6.

28 Ingebrigtsen T, Waterloo K, Marup-Jensen S, Attner E, Romner B. Quantification of postconcussion symptoms 3 months after minor head injury in 100 consecutive patients. J Neurol. 1998 Sep;245(9):609-12.

29 Edna TH, Cappelen J. Hospital admitted head injury. A prospective study in Trøndelag, Norway, 1979-80. Scand J Soc Med. 1984;12(1): 7-14.

30 Mauritz W, Brazinova A, Majdan M, Leitgeb $\mathrm{J}$. Epidemiology of traumatic brain injury in Austria. Wien Klin Wochenschr. 2014 Jan; 126(1-2):42-52.

31 Scholten AC, Haagsma JA, Panneman MJ, van Beeck EF, Polinder S. Traumatic brain injury in the Netherlands: incidence, costs and disability-adjusted life years. PLoS One. 2014 Oct;9(10):e110905.

32 Rickels E, von Wild K, Wenzlaff P. Head injury in Germany: A population-based prospective study on epidemiology, causes, treatment and outcome of all degrees of head-injury severity in two distinct areas. Brain Inj. 2010;24(12):1491-504

33 Servadei F, Verlicchi A, Soldano F, Zanotti B, Piffer S. Descriptive epidemiology of head injury in Romagna and Trentino. Comparison between two geographically different Italian regions. Neuroepidemiology. 2002 Nov-Dec; 21(6):297-304.

34 Tate RL, McDonald S, Lulham JM. Incidence of hospital-treated traumatic brain injury in an Australian community. Aust N Z J Public Health. 1998 Jun;22(4):419-23.

35 Ingebrigtsen T, Mortensen K, Romner B. The epidemiology of hospital-referred head injury in northern Norway. Neuroepidemiology. 1998;17(3):139-46.

36 McCrea M, Hammeke T, Olsen G, Leo P, Guskiewicz K. Unreported concussion in high school football players: implications for prevention. Clin J Sport Med. 2004 Jan;14(1):13-7.

37 Majdan M, Plancikova D, Brazinova A, Rusnak M, Nieboer D, Feigin V, et al. Epidemiology of traumatic brain injuries in Europe: a cross-sectional analysis. Lancet Public Health. 2016 Dec;1(2):e76-83.

38 Castile L, Collins CL, McIlvain NM, Comstock RD. The epidemiology of new versus recurrent sports concussions among high school athletes, 2005-2010. Br J Sports Med. 2012 Jun;46(8):603-10.

39 Bennett DA, Brayne C, Feigin VL, BarkerCollo S, Brainin M, Davis D, et al. Development of the standards of reporting of neurological disorders (STROND) checklist: a guideline for the reporting of incidence and prevalence studies in neuroepidemiology. Eur J Epidemiol. 2015 Jul;30(7):569-76. 